\title{
The effect of ultrasonographic measurement of vena cava inferior diameter on the prediction of post-spinal hypotension in geriatric patients undergoing spinal anesthesia
}

\author{
Yusuf Aslan ${ }^{1}$, Gulten Arslan ${ }^{1}$, Kemal Tolga Saracoglu², and Banu Eler Cevik ${ }^{2}$ \\ ${ }^{1}$ University of Health Sciences, Kartal Dr Lütfi Kırdar Training and Research Hospital, \\ Istanbul, Turkey \\ ${ }^{2}$ Istanbul Dr Lütfi Kırdar Kartal Eğitim ve Araştırma Hastanesi
}

April 27, 2021

\begin{abstract}
Aims: In our study,we aimed to investigate whether end-expiratory vena cava inferior (expVCI) diameter and vena cava inferior collapsibility index predicted post-spinal hypotension in geriatric patients undergoing spinal anesthesia, the correlation between them and other parameters. Material and methods: Our prospective study included ASA I-4,73 patients over 65 years of age, who were scheduled for operation using spinal anesthesia. According to the expVCI diameter displayed with USG before spinal anesthesia, patients; those with an expVCI diameter less than $1.8 \mathrm{~cm}$ previously determined as the threshold value are grouped as 1.(Small-VCI) Group,those greater than $1.8 \mathrm{~cm}$ as 2.(Large-VCI) Group. Demographic characteristics of the patients, comorbidities, duration and type of operation, basal (preoperative) heart rate, systolic, diastolic, mean blood pressure, peripheral oxygen saturation values before spinal anesthesia and after spinal anesthesia in supine position ( 0 min $)$ and 5 th, 10th, 15th, 20th, 25th, 30th min and preoperative arterial blood gas parameters, amount of peroperative urine and bleeding, inotropic and fluid requirement, complications were recorded. Results: Hypotension developed in 28(38.4\%) patients and bradycardia in 14 $(19.2 \%)$ of patients. The patients who developed hypotension had more ASA 2 and ASA $3(\mathrm{p}=0.01)$, shorter height ( $\mathrm{p}=0.02)$, and smaller $\operatorname{expVCI}$ diameter $(\mathrm{p}=0.004)$.It was observed that they had higher lactate $(\mathrm{p}=0.03)$, lower $\mathrm{pH}(\mathrm{p}=0.006)$ values, and more inotropic agents were administered $(\mathrm{p}<0.001)$. While the rate of developing hypotension was $51.1 \%(\mathrm{n}=23)$ in the patients in the Small-VCI group, this rate was $17.9 \%(\mathrm{n}=5)$ in the patients in the Large-VCI group ( $\mathrm{p}=0.004)$. Conclusion: It was concluded that the expVCI diameter value measured by USG before spinal anesthesia in elderly patients is effective in predicting post-spinal hypotension with lactate and $\mathrm{pH}$ values, which are among the blood gas parameters, and expVCI can be preferred to invasive methods due to its noninvasive, easy and fast application.
\end{abstract}

\section{Hosted file}

VCI-maintext_(2).pdf available at https://authorea.com/users/410218/articles/519686-theeffect-of-ultrasonographic-measurement-of-vena-cava-inferior-diameter-on-the-predictionof-post-spinal-hypotension-in-geriatric-patients-undergoing-spinal-anesthesia

\section{Hosted file}

VCI-table.pdf available at https://authorea.com/users/410218/articles/519686-the-effect-ofultrasonographic-measurement-of-vena-cava-inferior-diameter-on-the-prediction-of-postspinal-hypotension-in-geriatric-patients-undergoing-spinal-anesthesia

\section{Hosted file}


VCI-figure.pdf available at https://authorea.com/users/410218/articles/519686-the-effect-ofultrasonographic-measurement-of-vena-cava-inferior-diameter-on-the-prediction-of-postspinal-hypotension-in-geriatric-patients-undergoing-spinal-anesthesia 